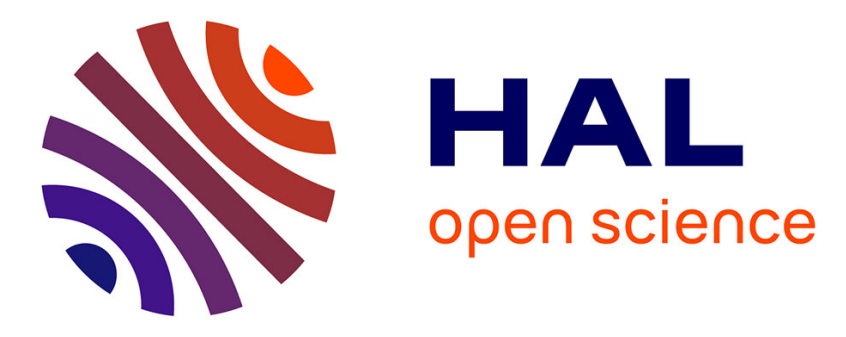

\title{
Chiral Memory in Silyl-Pyridinium and Quinolinium Cations
}

Anthony Fernandes, Claire Laye, Suman Pramanik, Dayvson Palmeira, Özgen Ömür Pekel, Stéphane Massip, Marc Schmidtmann, Thomas Müller, Frédéric Robert, Yannick Landais

\section{To cite this version:}

Anthony Fernandes, Claire Laye, Suman Pramanik, Dayvson Palmeira, Özgen Ömür Pekel, et al.. Chiral Memory in Silyl-Pyridinium and Quinolinium Cations. Journal of the American Chemical Society, 2020, 142 (1), pp.564-572. 10.1021/jacs.9b11704 . hal-02499360

\section{HAL Id: hal-02499360 https://hal.science/hal-02499360}

Submitted on 5 Mar 2020

HAL is a multi-disciplinary open access archive for the deposit and dissemination of scientific research documents, whether they are published or not. The documents may come from teaching and research institutions in France or abroad, or from public or private research centers.
L'archive ouverte pluridisciplinaire HAL, est destinée au dépôt et à la diffusion de documents scientifiques de niveau recherche, publiés ou non, émanant des établissements d'enseignement et de recherche français ou étrangers, des laboratoires publics ou privés. 


\title{
Chiral Memory in Silyl-Pyridinium and Quinolinium Cations.
}

\author{
Anthony Fernandes, ${ }^{\dagger}$ Claire Laye, ${ }^{\dagger}$ Suman Pramanik, ${ }^{\dagger}$ Dayvson Palmeira, ${ }^{\dagger}$ Özgen Ömür Pekel, ${ }^{\dagger}$ Stéphane Massip, ${ }^{\ddagger}$ Marc \\ Schmidtmann, ${ }^{\S}$ Thomas Müller, $^{\S}$ Frédéric Robert, ${ }^{\dagger}$ Y Yannick Landais ${ }^{\dagger} *$ \\ † Univ. Bordeaux, CNRS, ISM, UMR 5255, F-33400, Talence, France \\ ‡ Univ. Bordeaux, CNRS, IECB, UMS3033/INSERM US001, F-33607, Pessac, France \\ $\S$ Institute of Chemistry, Carl von Ossietzky University Oldenburg, Carl von Ossietzky-Str. 9-11, D-26211 Oldenburg, Germa- \\ ny, European Union.
}

KEYWORDS: Silicon, Silylium ions, Silyl cations, Si-centered chirality, chiral memory, boranates

ABSTRACT: Pyridine and quinoline-stabilized silyl cations have been prepared and their structure in condensed phases unambiguously assigned using ${ }^{1} \mathrm{H},{ }^{13} \mathrm{C},{ }^{15} \mathrm{~N},{ }^{29} \mathrm{Si}$ and ${ }^{1} \mathrm{H}$ DOSY NMR as well as $\mathrm{X}$-ray diffraction studies. Solid state structures thus show in both cases a stabilization of the cationic silicon center through an N-Si interaction and formation of a highly strained 4-membered ring system. Chiral memory at the silicon atom in these heterocycle-stabilized silyl cations was also established leading to various levels of selectivity depending on the nature of the heterocycle. Lowest energy conformations of the starting silanes obtained through DFT calculations, along with the isolation and characterization of the Sicentered chiral silyl cation intermediates finally allowed to propose a plausible hypothesis as to the configurational stability of these silyl cations.

\section{INTRODUCTION}

Silylium ions are extremely reactive species that are generally difficult to isolate and characterize, ${ }^{1}$ unless they are stabilized by coordination with a solvent or through an external or internal Lewis base (LB). ${ }^{2}$ This exacerbated reactivity has long delayed their isolation compared to carbocations, isolated and characterized nearly 100 years earlier. ${ }^{3}$ However, the pioneering work of Lambert and Reed made possible in $2002,{ }^{4}$ the characterization through X-ray diffraction studies of a silylium carborate with a truly tricoordinated silicon cation (e.g. $\mathrm{Mes}_{3} \mathrm{Si}^{+}{ }^{+} \mathrm{HCB}_{11} \mathrm{Me}_{5} \mathrm{Br}_{6}$ ), playing with the weakly nucleophilic nature of the carborane counter anion and the bulkiness of the mesityl substituents. The exceptional Lewis acidity of these cations has recently attracted a great deal of interest, as shown by examples of their use in catalysis, including Diels-Alder reactions, ${ }^{5}$ hydrodefluorination ${ }^{6}$ hydrogenation reactions using frustrated Lewis pairs ${ }^{7}$ or $\mathrm{CO}$ activation. ${ }^{8}$ However, these silicon species are only of synthetic interest if they are previously pacified and their reactivity controlled. The work of Siegel, Müller, Oestreich and others has shown that the interaction between the cationic silylated center and Lewis basic substituents is able to control this reactivity and to modulate the Lewis acidity of silicon. ${ }^{2}$ Very recent studies have demonstrated that the addition of basic and chiral ligands around the silyl cation not only stabilizes the latter but also allow chirality transfer with satisfactory enantioselectivity levels in Diels-Alder reactions. ${ }^{9}$ The labile nature of the weak LB-Si ${ }^{+}$interaction also favors the regeneration of the catalyst at the end of the catalytic cycle and could allow the use in asymmetric synthesis of silylium ions bearing a unique silicon-centered chirality, providing the latter is stable during the process. In this context, we have recently described silylium ions, presenting both axial and central chirality (on silicon), based on binaphthyl templates 1 and studied the conservation of silicon-centered chirality during silyl cation formation. ${ }^{10}$ It was shown that the magnitude of the LB-Si ${ }^{+}$interaction between the LB substituent and the silicon center could be evaluated looking at the configurational stability of the stereogenic silicon center in 1 (Figure 1). Conservation of the stereochemistry of the silicon center during the whole process (silyl cation formation/hydride addition) was thus observed in silylium ions stabilized by oxygen lone-pair interactions as in $\mathbf{1 a}^{+}$. While these experiments provide a satisfactory evaluation of the LB-Si interaction, they do not provide unambiguous answer about the configurational stability, throughout the process, of the stereogenic silicon center in the absence of a neighboring chirality. To address this point, we designed substrates $\mathbf{2}^{8 \mathrm{~b}}$ and $\mathbf{3}$ with a chirality centered only on the silicon atom and for which the stabilization of the silyl cation would be ensured by the nitrogen atom of a pyridine or a quinoline ring. The proximity between the Lewis basic center $(N)$ and the Si center should help the latter retaining most of its positive charge and thus its Lewis acidity, while R substituents on the heteroaromatic rings (e.g. I) were added to avoid intermolecular interactions. Stabilization through a 4- rather than a 5-membered ring has been privileged, based on reported high stability and low Lewis acidity of the silyl cation in the latter case. ${ }^{1 d, 1 f, 11}$ We report here on the evaluation of the configurational stability at the silicon atom in silyl cations, and provide experimental evidenc- 
es for this, including the X-ray diffractions studies of stabilized chiral silyl cations II. Based on these studies, a mechanism to rationalize the course of the $\mathbf{I} \rightarrow \mathbf{I I} \rightarrow$ III process is proposed (Figure 1 ).

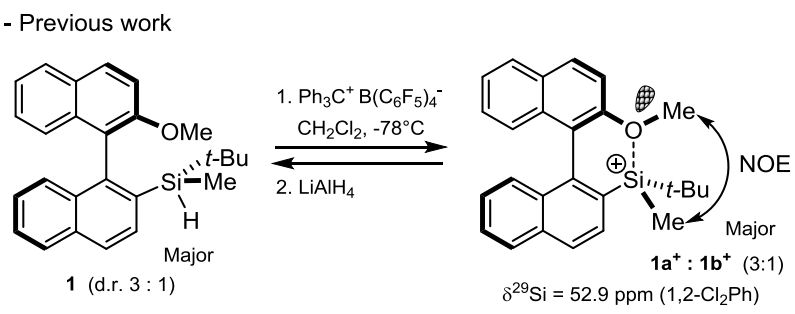

- This work
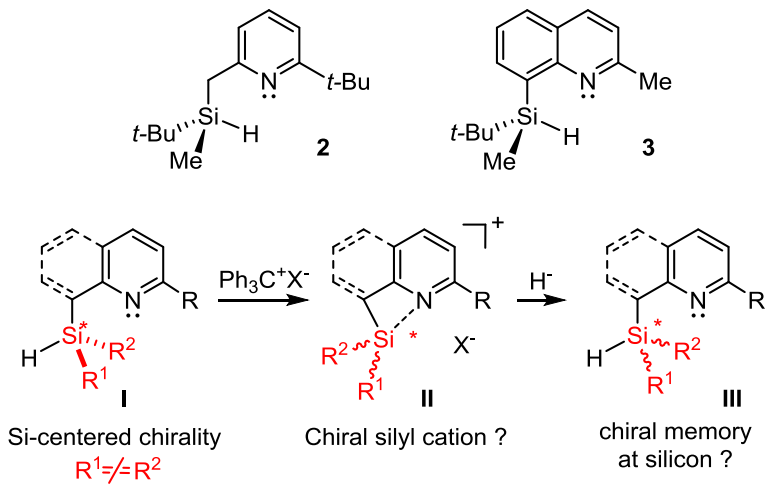

Figure 1. Chiral memory at silicon. Previous and current studies.

\section{RESULTS AND DISCUSSION}

Synthesis of optically active silanes $\mathbf{2}$ and $\mathbf{3}$. Racemic compound $\mathbf{2}$ was accessible through lithiation and silylation of the parent 2-(tert-butyl)-6-methylpyridine (72\% yield), ${ }^{8 b, 12 a-b}$ while $(+/-)-3$ was prepared starting from the corresponding quinoline bromide $\left(\mathrm{Br} \rightarrow \mathrm{Li}\right.$ exchange then silylation, $86 \%$ yield)(SI). ${ }^{12 \mathrm{C}}$ The resolution of both silanes was performed relying on a Pd-nanoparticle (Pd-NP) catalyzed dehydrogenative silylation of alcohols developed in our laboratory (Scheme 1). ${ }^{13}$ Using (-)-menthol, the silane $\mathbf{2}$ was thus converted into the corresponding diastereomeric silyl ethers $\mathbf{4 a - b}$, which were separated through silica gel chromatography. Reduction of diastereomerically pure $\mathbf{4 a}$ and $\mathbf{4 b}$ using DIBAL-H, ${ }^{9 a, 14}$ (known to proceed with retention of configuration), ${ }^{15}$ finally afforded silanes $(+)-\mathbf{2}$ and (-)-2. The measurement of the enantiomeric excess of enantiomers of $\mathbf{2}$ proved particularly difficult to achieve using chiral HPLC. Although, $\mathbf{2}$ was found to be quite sensitive to acids, leading to desilylation, ${ }^{16}$ the enantiomeric purity of 2 was eventually estimated at $-20^{\circ} \mathrm{C}$ relying on the ${ }^{1} \mathrm{H}$ NMR integration of the Si-H multiplet of the salt $\mathbf{6}$ prepared from rac-2, (-)-2 or (+)-2 and (R)-BINOL-dithiophosphoric acid (R-BINOL-PSSH). ${ }^{17,18}$ The same approach was then applied to silane 3, whose reaction with (-)-menthol produced the expected silyl ethers, which proved to be inseparable. When the reaction was repeated using instead (-)-borneol, silyl ethers $\mathbf{5} \mathbf{a}-\mathbf{b}$ were isolated, then readily separated through selective crystallization, affording diastereomerically pure $\mathbf{5 a}$ and $\mathbf{5 b}$. The $S, S, R, S_{S i}$ configuration of $\mathbf{5 b}$ was assigned unambiguously through $X$-ray diffraction studies (Scheme 1 ). Reduction of $\mathbf{5 a}$ and $\mathbf{5 b}$ as above, finally afforded enantiopure R-(-)-3 and S-(+)-3 respectively, which enantiomeric excesses could be measured through chiral HPLC (SI).

Scheme 1. Synthesis of optically pure silanes 2 and 3. 

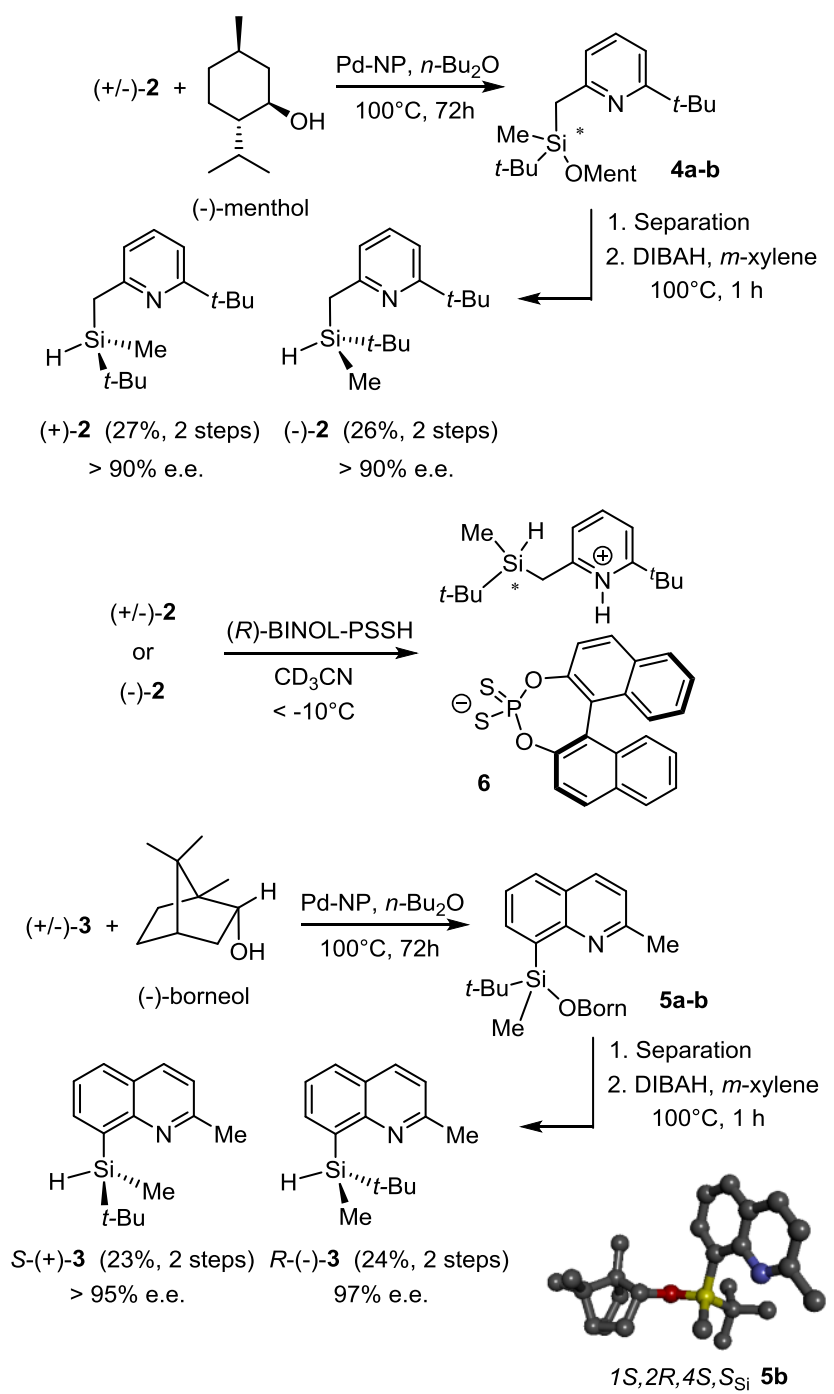

Generation of silyl cations 7, 8a-b and NMR studies. Abstraction of the Si-H hydrogen in silanes $\mathbf{2}$ and $\mathbf{3}$, following the Corey hydride transfer reaction, ${ }^{19}$ using $\left[\mathrm{Ph}_{3} \mathrm{C}\right]\left[\mathrm{B}\left(\mathrm{C}_{6} \mathrm{~F}_{5}\right)_{4}\right]$ or $\left[\mathrm{Ph}_{3} \mathrm{C}_{2}\left[\mathrm{~B}_{12} \mathrm{Br}_{12}\right]\right.$ led respectively to the corresponding silylpyridinium 7 and silylquinolinium 8a-b salts (Scheme 2), which were first characterized by multinuclear NMR spectroscopy, including ${ }^{29} \mathrm{Si}$ and ${ }^{15} \mathrm{~N}$ NMR (Table 1). ${ }^{20}$ Chemical shifts in ${ }^{29} \mathrm{Si} \mathrm{NMR}$ were observed at $57.9 \mathrm{ppm}$ for $\mathbf{7}$ and $63.8 \mathrm{ppm}$ for

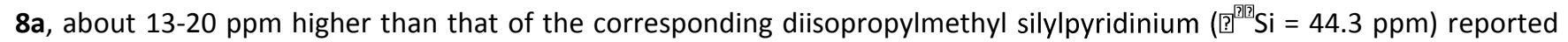
by Lambert and co-workers, ${ }^{21}$ indicative of a putative $\mathrm{Si}^{+}-\mathrm{N}$ interaction (i.e. II, Figure 1 ). These values are in good agreement with chemical shifts estimated through DFT calculations (GIAO M06L/def2-TZVPP//M06-2X/def2-TZVPP) on 7 and 8a (SI). The occurrence of an interaction between the pyridine or quinoline nitrogen and the silylium in $\mathbf{7}$ and $\mathbf{8 a}$ was further supported through ${ }^{15} \mathrm{~N}$ NMR spectroscopy. For instance, for salt 7 and its precursor 2 , $0^{15} \mathrm{~N}=-153.4 \mathrm{ppm}$ and $-69.3 \mathrm{ppm}$ were observed respectively, consistent with the formation of a pyridinium ion (] $=-84.1 \mathrm{ppm}$ ). Similar results have been described by Moore et al. for a pyridinium-trifluoroborate, ${ }^{22}$ with a chemical shift variation from free pyridine (]$^{15} \mathrm{~N}=-67.7$ $\mathrm{ppm}$ ) to the Lewis adduct ( $]^{15} \mathrm{~N}=-143.3 \mathrm{ppm}$ ) leading to a ] $=-75.6 \mathrm{ppm}$. A similar observation was made for salt 8a, with $\mathrm{a}$ ] $=-\mathbf{9 8 . 1} \mathrm{ppm}$ between $\mathbf{3}$ and $\mathbf{8} \mathrm{a}$. In order to distinguish between $\mathrm{Si}-\mathrm{N}$ interactions resulting from intra- or intermolecular association (involving for instance two molecules of silyl cations), DOSY (Diffusion Ordered Spectroscopy) ${ }^{23}$ experiments were carried out. Diffusion coefficient values (see SI) of $4.60 \times 10^{-10} \mathrm{~m}^{2} \mathrm{~s}^{-1}$ for $\mathrm{Ph}_{3} \mathrm{CH}$ (for a molecular weight $\mathrm{M}_{\text {Ph3cH }}=$ $\left.244.330 \mathrm{~g} \cdot \mathrm{mol}^{-1}\right)$ and $3.47 \times 10^{-10} \mathrm{~m}^{2} \mathrm{~s}^{-1}$ for the salt $7\left(\mathrm{MW}=927.495 \mathrm{~g} \cdot \mathrm{mol}^{-1}\right)$ were measured. The latter value is very similar to that obtained for trityl tetrakis(pentafluorophenyl)borate $\left(3.69 \times 10^{-10} \mathrm{~m}^{2} \mathrm{~s}^{-1}\right)$, which has a molecular weight of 922.358 g. $\mathrm{mol}^{-1}$ (when behaving as a tight ion-pair in non-polar solvent ${ }^{24}$ ), indicating that $\mathbf{7}$ is a monomeric species and that the N-Si interaction is as shown in Scheme 2. The same conclusion could be drawn from DOSY experiments performed on salt 8a (SI).

Scheme 2. Synthesis of salts 7 and $8 a-b$ (in $8 b$ two silyl cations are associated to dianionic closo-boranate). 

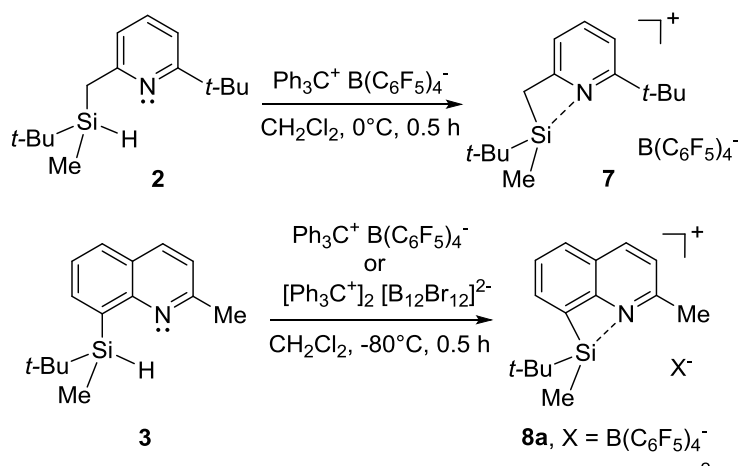

$\mathbf{8 b}, \mathrm{X}=\left[\mathrm{B}_{12} \mathrm{Br}_{12}\right]^{2-}$

X-ray diffraction studies of silyl cation 7. Evidence of the N-Si stabilization and consequently of the formation of a 4membered ring system was finally obtained through crystal structure of $\mathbf{7}$. After numerous unsuccessful trials, we were able to get crystals of the salt $\mathbf{7}$ from a toluene-pentane mixture at $-18^{\circ} \mathrm{C}$ and to perform X-ray diffraction studies (XRDS). The molecular structure of $\mathbf{7}$ shows a significant separation between the cation and the borate anion as indicated in Figure $2 \mathrm{a}$, with distances (Si-F, N-F and H-F) that are significantly higher than the sum of the van der Waals radii of the corresponding atoms $\left(\Sigma r_{v d W, S i / F}=3.57 \AA\right.$ 列 $r_{v d W, N / F}=3.02 \AA$ and $\Sigma r_{v d W, H / F}=2.57 \AA$ with $r_{v d W, H}=1.10 \AA, r_{v d W, F}=1.47 \AA, r_{v d W, N}=1.55 \AA$ and $\left.r_{v d w, s i}=2.10 \AA\right)$. The solid state structure of 7 also exhibits a N-Si bond length of $1.892 \AA$, slightly longer than that reported for the trimethylsilylpyridinium iodide $(1.858 \AA)^{25}$ and much longer than that expected for an iminosilane N-Si bond $(1.73$ $\AA),{ }^{26}$ reflecting the presence of a highly polarized bond (Table 1). Pyramidalization of the silicon center in 7 was assessed through the sum of the covalent bond angle around $\mathrm{Si}\left(\Sigma \alpha(\mathrm{Si})=345.02^{\circ}\right.$, Table 1$)$, and is less pronounced than that in the trimethylsilylpyridinium iodide $\left(\Sigma \alpha(\mathrm{Si})=340.8^{\circ}\right)$, yet revealing a rather large distortion from trigonal planar geometry $(\Sigma \alpha(\mathrm{Si})$ $\left.=360^{\circ}\right)$, which indicates that this system is getting as expected quite far from a true silylium ion. The most prominent feature of this crystal structure arose from a significant deformation of the bond angles in 7, revealing the important constraint resulting from the formation of the nearly planar four-membered ring $\left(\mathrm{C}_{1}-\mathrm{C}_{2}-\mathrm{N}-\mathrm{Si}\right.$, 目=3.0 $\left.0^{\circ}\right)$, with a $\mathrm{C}_{2}-\mathrm{C}_{1}-\mathrm{Si}$ angle ? of $87.93^{\circ}$ (instead of $109^{\circ}$ in 2 ), and the sum of the angles around the nitrogen of $\Sigma \alpha(\mathrm{N})=359.85^{\circ}$, very close to the ideal value. It is interesting to note that all these experimental data are well reflected in the molecular structure calculated by DFT (Table 1 and SI). Finally, the analysis of the optimized wave function of $\mathbf{7}$ indicates that the LUMO is not centered on the silicon atom but is rather a ?-orbital of the pyridine moiety with significant contributions from the silicon atom (Figure $2 b)^{27}$

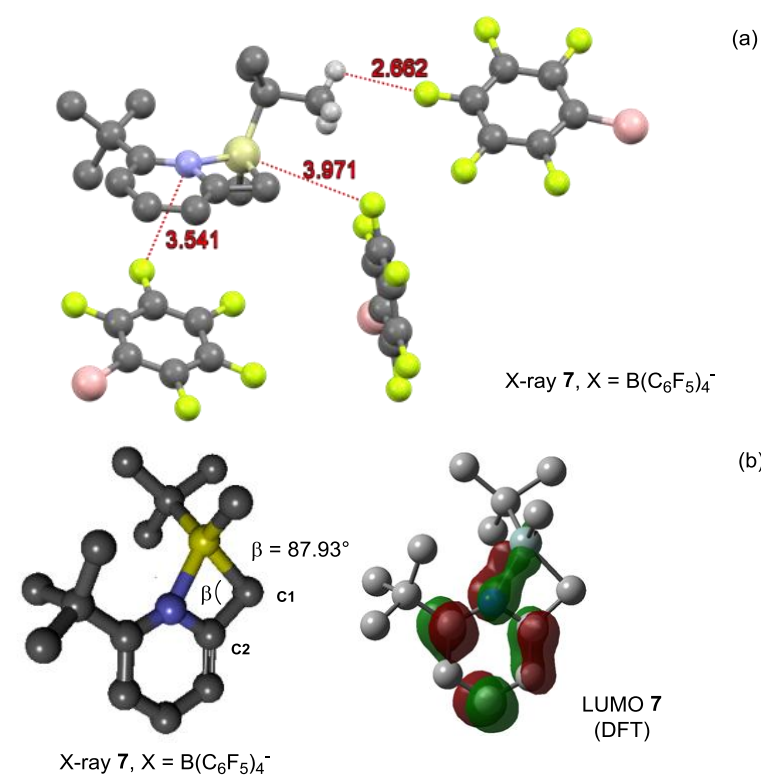

Figure 2. (a) Molecular structure of salt 7 with closest contacts and distances between cation and $B\left(\mathrm{C}_{6} \mathrm{~F}_{5}\right)_{4}$ anions in the crystal (yellow: Si; green: F; Blue: N; Grey: H; Pink: B). (b) Perspective view of the molecular structure of the silyl cation of 7 in the crystal (anion omitted) with its calculated LUMO (M06-2X/def2-TZVPP, at an isodensity value of 0.02). 
Table 1: Comparison between experimental and calculated values of structural and NMR parameters for crystals of $7,8 a$ and $8 \mathrm{~b}$.

\begin{tabular}{ccc}
\hline Parameters & Exp. & Calc. $^{\text {a }}$ \\
\hline $\mathrm{d}_{\mathrm{N}-\mathrm{Si}}(\mathbf{7})$ & $1.892 \AA$ & $1.886 \AA$ \\
$\Sigma \alpha(\mathrm{Si})(\mathbf{7})$ & $345.02^{\circ}$ & $345.82^{\circ}$ \\
$\Sigma \alpha(\mathrm{N})(\mathbf{7})$ & $359.85^{\circ}$ & $359.99^{\circ}$ \\
$\alpha \mathrm{C}_{1} \mathrm{C}_{2} \mathrm{NSi}(\mathbf{7})$ & $3.0^{\circ}$ & $2.12^{\circ}$ \\
{$\left[^{29} \mathrm{Si}(\mathbf{7})\right.$} & $57.9 \mathrm{ppm}$ & $55.6 \mathrm{ppm}$ \\
$\mathrm{BDE}(\mathrm{N}-\mathrm{Si}) \mathbf{7}$ & - & $42 \mathrm{kcal} \mathrm{mol}^{-1}$ \\
\hline $\mathrm{d}_{\mathrm{N}-\mathrm{Si}}$ (8b) & $1.886 \AA$ & $1.889 \AA$ \\
$\Sigma \alpha(\mathrm{Si})(\mathbf{8 b})$ & $352.76^{\circ}$ & $352.76^{\circ}$ \\
$\Sigma \alpha(\mathrm{N})(\mathbf{8 b})$ & $359.76^{\circ}$ & $359.99^{\circ}$ \\
$\alpha \mathrm{C}_{1} \mathrm{C}_{9} \mathrm{NSi}(\mathbf{8 b})$ & $-2.38^{\circ}$ & $-0.95^{\circ}$ \\
{[]$^{29} \mathrm{Si}(\mathbf{8 a})$} & $63.8 \mathrm{ppm}$ & $63.0 \mathrm{ppm}^{\circ}$ \\
$\mathrm{BDE}(\mathrm{N}-\mathrm{Si}) 8 \mathrm{a}$ & - & $34 \mathrm{kcal} \mathrm{mol}^{-1}$ \\
\hline
\end{tabular}

${ }^{\text {a }}$ DFT calculations performed at M06-2X/def2-TZVPP level for geometries and GIAO M06L/def2-TZVPP//M06-2X/def2-TZVPP for NMR predictions.

X-ray diffraction studies of silyl cation $\mathbf{8 b}$. While our attempts to crystallize $\mathbf{8 a}$ under similar conditions were not successful, better results were obtained with boranate-based silyl cation $\mathbf{8 b},{ }^{28}$ which led to crystals suitable for XRDS in mixtures of $\mathrm{CH}_{2} \mathrm{Cl}_{2}$, with slow diffusion of hexane or toluene at room temperature. The bis-silyl boranate $\mathbf{8 b}$ crystallizes with two molecules of $\mathrm{CH}_{2} \mathrm{Cl}_{2}$ (Figure 3) and is well separated from the boranate dianion with the shortest distance between the silicon center and bromine atoms on the anion moiety of $4.814 \AA$. As for 7, the shortest distances are those between bromine and hydrogen atoms, yet higher than the sum of the van der Waals radii of the $\mathrm{H}$ and $\mathrm{Br}$ atoms $\left(\sum \mathrm{r}_{\mathrm{vdW}, \mathrm{H} / \mathrm{Br}}=2.85 \AA\right.$, and $\Sigma \mathrm{r}_{\mathrm{vdW}, \mathrm{C} / \mathrm{Br}}$ $=3.55 \AA$, with $r_{v d W, C}=1.70 \AA, r_{v d W, H}=1.10 \AA, r_{v d W, B r}=1.85 \AA$ ). Interestingly, while the anion is maintained quite far away from silicon, a proximity is observed between boranate bromine atoms and quinoline carbon centers (Figure 3 ). Although a packing effect cannot be completely ruled out, it may also be indicative of a delocalization of the silylium positive charge over the heteroaromatic ring, as supported by the calculated LUMO of $8 \mathrm{a}$. Similarly to 7 , deviation of the $\mathrm{C}_{9}-\mathrm{C}_{1}-\mathrm{Si}$ angle (? $\mathrm{?}=$ $88.76^{\circ}$ ) in $\mathbf{8 b}$, from the geometry of the parent silane $S-(+)-\mathbf{3}\left(\right.$ ? $=121.59^{\circ}$ ) is remarkable. Several differences may however be noticed between $\mathbf{7}$ and $\mathbf{8 b}$ as shown in Figures 2-3 and Table 1. N-Si bond length is slightly shorter in $\mathbf{8 b}$ relative to $\mathbf{7}$ (1.886 $\AA$ vs $1.892 \AA$ ). While a remarkable distortion of the $C_{A r}\left(C_{2}\right.$ or $\left.C_{9}\right)-C_{1}-S i$ angle is observed in both 7 and $8 b$, relative to that in silane precursors $\mathbf{2}$ and $\mathbf{3}$ (vide supra), the deviation is more pronounced for $\mathbf{8 b}$ (? ? ? $\left.=32.83^{\circ}\right)^{29}$ relative to $\mathbf{7}($ ? ? $=$ $21.07^{\circ}$ ), suggesting a higher angle strain in the former. In addition, the silicon atom in $\mathbf{8 b}$ shows a trigonal pyramidal coordination with an almost planar base $\left(\Sigma \alpha(\mathrm{Si})=352.76^{\circ}\right.$, Table 1$)$, leaving more space (than in 7$)$ for an apical approach of any reagent on the silicon center (vide infra). Bond dissociation energies, estimated using isodesmic equations (see SI) showed that $\mathrm{N}$-Si bond in 7 was meaningfully stronger than that in $8 \mathrm{a}$ (42 and $34 \mathrm{kcal}^{\mathrm{mol}}{ }^{-1}$ respectively), in line with the larger angle strain mentioned above for $\mathbf{8 b}$. Recent studies by Müller and co-workers on chalcogen-Si interaction in less strained 5-membered ring peri-naphthyl chalconium-silyl borates, using the same approach, led to BDE around $50 \mathrm{kcal}^{\mathrm{mol}}{ }^{-1}$, indicating a strong correlation between angle strain and heteroatom-Si ${ }^{+}$bond strength. ${ }^{6 i}$ 

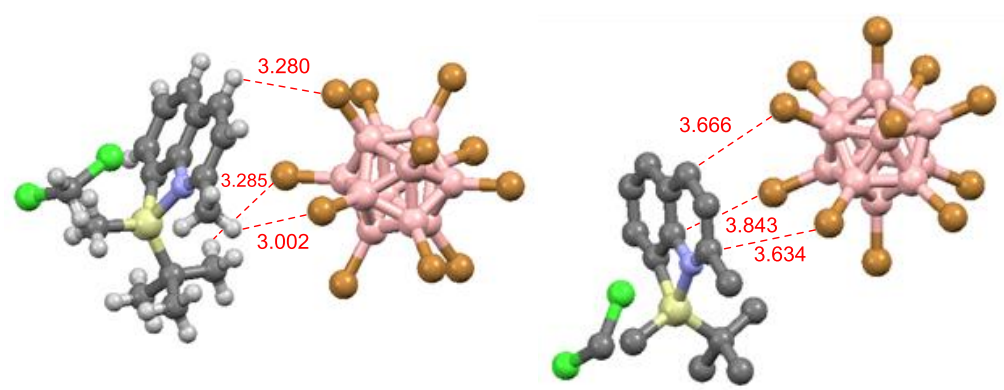

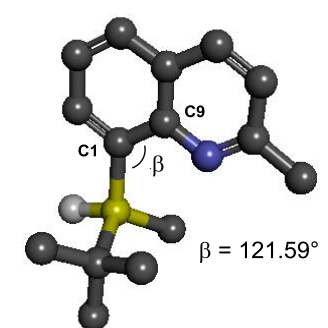

X-ray $S-(+)-3$

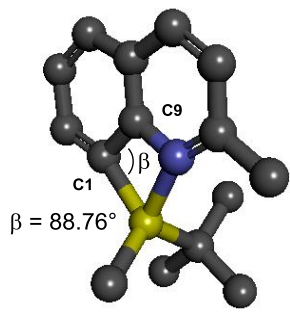

X-ray $\mathbf{8 b}, \mathrm{X}=\left[\mathrm{B}_{12} \mathrm{Br}_{12}\right]^{2-}$

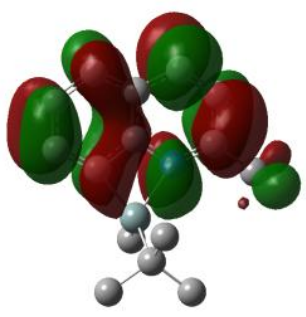

LUMO 8a (DFT)

Figure 3. Molecular structure of silylium closo-boranate ion pair $\mathbf{8 b}$ and $\mathrm{CH}_{2} \mathrm{Cl}_{2}$ (solvent) with closest contacts and distances between cations and anions in the crystal (brown: $\mathrm{Br}$; one silyl cation symmetrically linked to boranate dianion has been omitted for clarity). Perspective views of molecular structures of silane S-(+)-3 and cation of $\mathbf{8 b}$ in the crystal (anion omitted). Calculated LUMO of cation of 8a (M06-2X/def2-TZVPP, at an isodensity value of 0.02).

Studies on the chiral memory in silanes $\mathbf{2}$ and $\mathbf{3}$. With the structural data in hands, investigations on the chiral memory in salts 7 and 8a were then carried out, following the strategy developed for binaphthyl systems $\mathbf{1}$ (Figure 1 ). ${ }^{10}$ Silylium borates were prepared as described above, then quenched with hydride donors at different temperatures, and the enantiopurity of the final silanes $\mathbf{2}$ and $\mathbf{3}$ evaluated as above. It is important noticing that for each experiment, the disappearance of the silane and formation of the silyl cation intermediates 7 or 8 a were checked, through ${ }^{1} \mathrm{H}$ and ${ }^{29} \mathrm{Si}$ NMR, before addition of the hydride. The whole sequence was first tested using silane (+/-)-2 and $\mathrm{Bu}_{3} \mathrm{SnH}$ as a hydride donor (2 eq.), which led to recovery of $\mathbf{2}$ in a $47 \%$ overall yield for the silylium ion formation/reduction sequence (entry 1, Table 2). This moderate yield was attributed to the decomposition of the silane in the medium due to the presence of traces of protons resulting from the decomposition of tributylstannyl species. ${ }^{30,31}$ The reaction was thus repeated in the presence of 2 equivalents of the Hünig's base ( $i$ - $\left.\operatorname{Pr}_{2} \mathrm{NEt}\right)$ at room temperature. Under these conditions, (+/-)-2 was recovered in an improved $76 \%$ NMR yield (entry 2, Table 2). The sequence was then applied to enantiopure (-)-2, which enantiopurity was estimated directly from the crude reaction mixture, as illustrated in Scheme 1. Under these conditions, we observed that chirality was lost to a large extent (from > $90 \%$ to $14 \%$ e.e., entry 3, Table 2). Reasoning that the high temperature and the presence of the Hünig's base might be responsible for the loss of chirality, the search for an alternative hydride donor leading to cleaner reaction mixture was envisaged. $n-\mathrm{Bu}_{4} \mathrm{NBH}_{4}$, which is soluble in organic solvents and easy to discard at the end of the whole sequence, appeared as a good candidate, allowing the reaction to be carried out at a lower temperature, and avoiding traces of alkyltin residues in the final product. These new reaction conditions were first tested on (+/-)-2, leading to good recovery of the silane $(67 \%$, entry 4 , Table 2$)$. When the silylium ion was generated from enantiopure $(-)-2$ at $0{ }^{\circ} \mathrm{C}$, then treated with ${ }^{n} \mathrm{Bu}_{4} \mathrm{NBH}_{4}$ at the same temperature, 2 was recovered with complete retention of configuration (entry 5 , Table 2). Similar conditions were then applied to silane 3, which upon treatment with $\left[\mathrm{Ph}_{3} \mathrm{C}\right]\left[\mathrm{B}\left(\mathrm{C}_{6} \mathrm{~F}_{5}\right)_{4}\right]$, then $n-\mathrm{Bu}_{4} \mathrm{NBH} \mathrm{H}_{4}$ in $\mathrm{CH}_{2} \mathrm{Cl}_{2}$ led to recovered 3 in good overall yield, but complete racemization at $25^{\circ} \mathrm{C}$ (entry 6, Table 2). Configurational stability of silyl cation $\mathbf{8 a}$ was found to be much lower than that of $\mathbf{7}$, as the whole reaction sequence performed at $-80^{\circ} \mathrm{C}$ led to enantioselectivities ranging between $40 \%$ to $60 \%$, whatever the enantiomer of 3 used during the process (entries $7-8$, Table 2). 
Table 2: Studies on chiral memory on silanes 2 and 3.

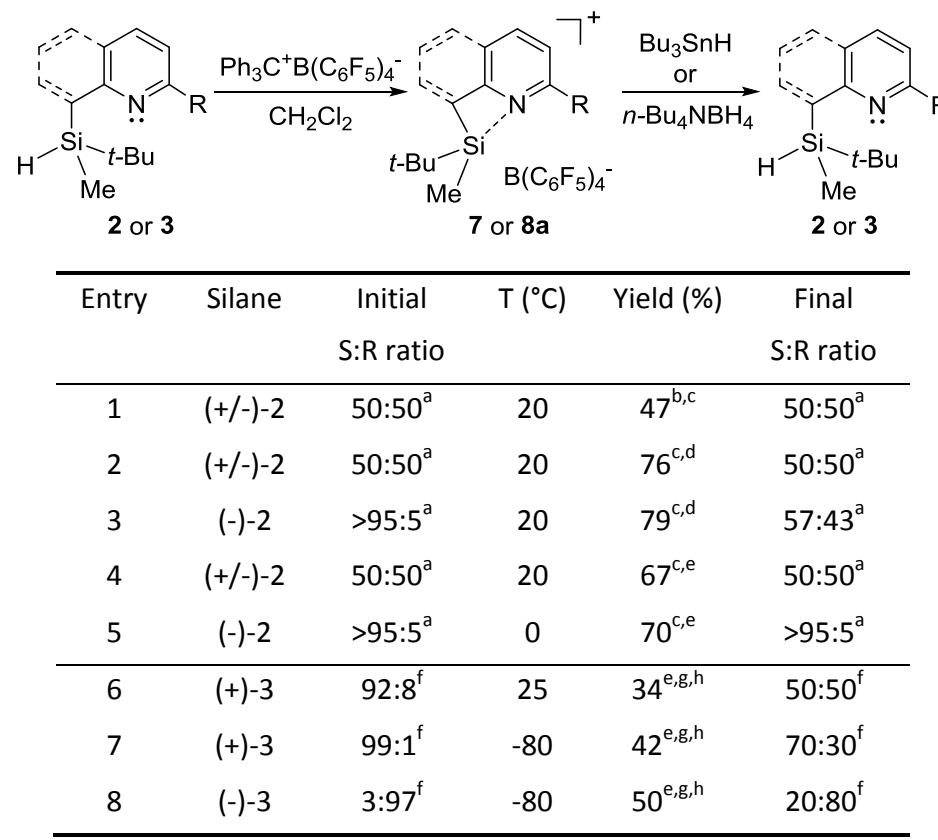

${ }^{a}$ Ratio estimated using ${ }^{1} \mathrm{H}$ NMR of dithiophosphate salt 6 (Scheme 1). ${ }^{b} \mathrm{Bu}_{3} \mathrm{SnH}$ (2 eq.) was used in the second step. ${ }^{\mathrm{c}} \mathrm{H}$ NMR yield using mesitylene as an internal standard. ${ }^{d} \mathrm{Bu}_{3} \mathrm{SnH}$ (2 eq.) and $i-\mathrm{Pr}_{2} \mathrm{NEt}$ (2 eq.) were used in the second step. ${ }^{\mathrm{e}} n$ - $\mathrm{Bu}_{4} \mathrm{NBH}_{4}$ was used in the second step. ${ }^{f}$ ratio measured through chiral HPLC (SI). ${ }^{g}$ Isolated yield after chromatography. ${ }^{\mathrm{h}}{ }^{\mathrm{H}} \mathrm{NMR}$ yield using mesitylene as an internal standard ranged between 65 and $70 \%$.

Conformational and spectroscopic studies on silanes $\mathbf{2}$ and $\mathbf{3}$. These experiments thus establish the generation for the first time of an enantiopure stabilized silyl cation, in which the configurational stability of the stereogenic silicon center depends on the nature of the Lewis basic heterocycle interacting with silicon. The overall retention of configuration observed in silane $\mathbf{2}$ over the two-step sequence ( $\mathrm{Si}-\mathrm{H}$ abstraction/reduction) must therefore results either from a double inversion or a double retention of configuration at silicon. The reactive conformation of the starting silanes in the first step and the configurational stability of the silyl cation (e.g. the strength of the N-Si interaction) in the second step are thus keyelements to consider in order to draw a plausible mechanism of the process. Conformational studies on silanes (-)-2 and $\mathbf{S}$ (+)-3 were thus carried out through DFT calculations in order to assess if silanes exhibit conformational preferences that might influence the stereochemical course of the Si-H hydrogen abstraction. In order to minimize the number of conformations, calculations on silane $\mathbf{2}$ were performed using a $\mathrm{Sit}-\mathrm{Bu}_{2} \mathrm{H}$ group instead of the Sit-BuMeH used experimentally, assuming that this modification would have a minor impact on the final conformations. The analysis of silane $\mathbf{2}\left(\boldsymbol{t}-\mathbf{B} \mathbf{u}_{\mathbf{2}}\right)$ thus led to 3 major conformations of lower energy noted $\mathbf{2 A}, \mathbf{2} \mathbf{A}^{\prime}$ and $\mathbf{2} \mathbf{A}^{\prime \prime}$ (Figure 4). Relative energies, along with distances between $\mathrm{N}$ and $\mathrm{Si}$ and $\mathrm{Si}-\mathrm{H}$ bond lengths indicate that the low energy conformations $\mathbf{2 A}$ and $\mathbf{2 A ^ { \prime }}$ exhibit the longest Si-H bond. Interestingly, $\mathbf{2} \mathbf{A}^{\prime}$ only $0.2 \mathrm{kcal} / \mathrm{mol}$ higher than $\mathbf{2 A}$, is also the conformation in which the N-Si distance is the lowest (3.2201 $\AA$ ), inferior to the sum of the van der Waals radii for Si and N (3.5 $\AA$ ), suggesting a more important interaction between $\mathrm{N}$ and $\mathrm{Si}$ in this conformation, in line with a weaker $\mathrm{Si}-\mathrm{H}$ bond, ${ }^{32}$ as observed in pentacoordinate silicon species. ${ }^{33}$ Conformation 2A" also exhibits a short $\mathrm{d}_{\mathrm{N}-\mathrm{S} \text {, }}$ but a shorter $\mathrm{Si}-\mathrm{H}$ bond length, likely resulting from an electronic repulsion between the nitrogen lone pair and the $\mathrm{Si}-\mathrm{H}$ bond that face each other. Calculations were then carried out on silane $\mathbf{3}$ (the higher rigidity of $\mathbf{3}$ allowing the use of the Sit-BuMeH substituent), which led only to two low energy conformations $\mathbf{3 A}$ and 3A' (Figure 4). Conformation $\mathbf{3 A}$ exhibits a Si-H hydrogen pointing away (nearly anti) from the nitrogen center (as in $\mathbf{2} \mathbf{A}^{\prime}$ ), 2 kcal.mol ${ }^{-1}$ lower than conformation $\mathbf{3} \mathbf{A}^{\prime}$ with the hydrogen facing the quinoline nitrogen lone pair. It is worthy of note that a conformation close to that of $\mathbf{3 A}$ is also observed in the solid state (Figure 3). Furthermore, a sum of the bond angles around silicon of $338,3^{\circ}$ is measured in silane $\mathbf{3}$ crystal, indicating a significant trigonal flattening of silicon. Interestingly, the $\mathrm{Si}-\mathrm{H}$ bond length in $\mathbf{3 A}$ is much longer than that in $\mathbf{3} \mathbf{A}^{\prime}$, these conformations also showing short $\mathbf{N}-\mathrm{Si}$ distances as in $\mathbf{2 A}$ and $\mathbf{2} \mathbf{A}^{\prime}$ above. These calculations therefore suggest that silanes $\mathbf{2}$ and $\mathbf{3}$ have low energy conformations in which the Si- $\mathrm{H}$ bond is already elongated such that these conformations should have a higher reactivity toward trityl abstraction. This was fur- 
ther substantiated with calculations of lower energy conformations of a silane such as 9, bearing a naphthyl instead of a quinolyl substituent, thus lacking the $\mathrm{N}-\mathrm{Si}$ interaction. This led to two conformations 9A-9A', which resemble conformations 3A-3 $\mathbf{A}^{\mathbf{\prime}}$ of silane 3. However, in contrast to the latter, $\mathbf{9 A}$ and $\mathbf{9} \mathbf{A}^{\mathbf{\prime}}$ are close in energy, exhibit similar Si-H bond lengths, and no lengthening of the Si-H bond as observed with $\mathbf{3 A}$ (relative to $\mathbf{3} \mathbf{A}^{\prime}$ ). Examination of NMR and FT-IR data however did not provide clear experimental evidence of such a $\mathrm{N}-\mathrm{Si}$ interaction in neutral silanes in solution. An interaction between $\mathrm{N}$ and Si should affect the Si-H bond energy, which would be reflected in the ? $_{\mathrm{Si}-\mathrm{H}}$ absorption. ? $_{\mathrm{Si}-\mathrm{H}}$ in silane 9 (? $=2116 \mathrm{~cm}^{-1}$ ), lacking the N-Si interaction, is effectively larger by $25 \mathrm{~cm}^{-1}$, as compared to those of $\mathbf{2}$ and $\mathbf{3}$, exhibiting Si-H stretching frequencies respectively at 2107 and $2091 \mathrm{~cm}^{-1}$, indicating a slightly weaker $\mathrm{Si}-\mathrm{H}$ bond in $\mathbf{2}$ and $\mathbf{3}$. Chemical shift of the nitrogen center in silanes 2 and 3, at -69.3 and -66.7 ppm, are however close to that of the free pyridine (-67.7 ppm), suggesting little perturbation around the nitrogen center in the silanes and thus a weak interaction with silicon if any. Finally, chemical shift of 2.3 and $2.2 \mathrm{ppm}$ in ${ }^{29} \mathrm{Si}$ are more downfield than expected for a silicon center interacting with a ligand in a pentacoordinated fashion. ${ }^{34}$ All these spectroscopic data indicate that if an interaction exists between $\mathrm{N}$ and $\mathrm{Si}$, it must be weak, which is confirmed by DFT computational studies. It thus appears reasonable to assume that low energy conformations such as $\mathbf{2} \mathbf{A}^{\prime}$ and $\mathbf{3 B}$, having elongated $\mathrm{Si}-\mathrm{H}$ bonds resulting from a weak interaction between $\mathrm{N}$ and $\mathrm{Si}$ may be the reactive conformations during abstraction, the trityl cation approaching anti relative to the nitrogen, leading to chiral silyl cations 7-8 with inversion of configuration (vide infra, Figure 5). Extensive efforts to access the transition state energy of this step through DFT calculations unfortunately failed. 

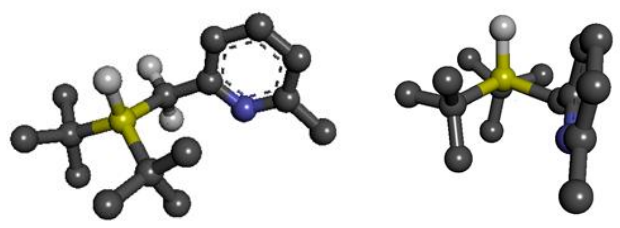

2A (Front view)

2A (Side view)
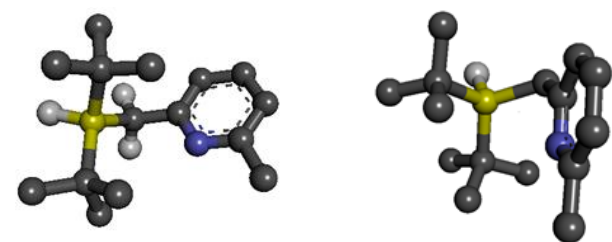

2A' (Front view)

2A' (Side view)
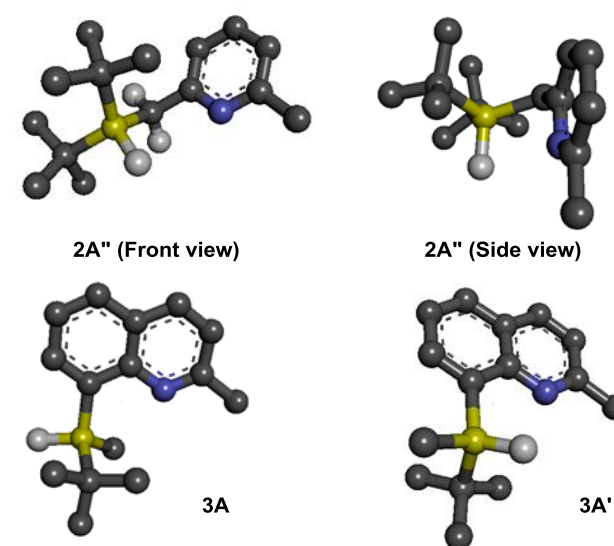

2A" (Side view)<smiles>CC(C)(C)[Si]([SiH3])(c1cccc2ccccc12)C(C)(C)C</smiles>
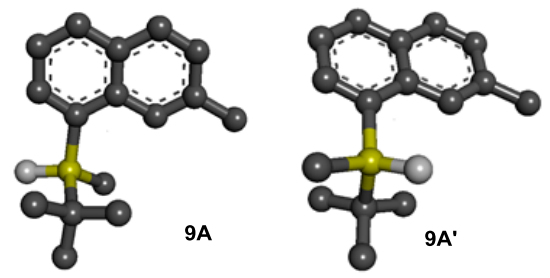

\begin{tabular}{cccc}
\hline conformation & $\begin{array}{c}\text { energy } \\
\text { kcal/mol }\end{array}$ & $\begin{array}{c}\mathrm{d}_{\mathrm{N}-\mathrm{Si}} \\
(\AA \AA)\end{array}$ & $\begin{array}{c}\mathrm{d}_{\mathrm{Si}-\mathrm{H}} \\
(\AA \AA)\end{array}$ \\
\hline $\mathbf{2 A}$ & 0 & 3.6863 & 1.4902 \\
$\mathbf{2 A ^ { \prime }}$ & +0.2 & $\mathbf{3 . 2 2 0 1}$ & $\mathbf{1 . 4 9 2 5}$ \\
$\mathbf{2 A ^ { \prime \prime }}$ & +1.1 & 3.2698 & 1.4835 \\
\hline $\mathbf{3 A}$ & 0 & $\mathbf{3 . 0 7 6 6}$ & $\mathbf{1 . 4 8 8 7}$ \\
$\mathbf{3 A}$ & +2.0 & 3.0701 & 1.4786 \\
\hline $\mathbf{9 A}$ & +0.4 & - & 1.4849 \\
$\mathbf{9 A}$ & 0 & - & 1.4844
\end{tabular}

Figure 4. Calculated (DFT) conformations of silanes $\mathbf{2}, \mathbf{3}$ and $\mathbf{9}$ with their energies and bond lengths.

Mechanism proposal. Overall retention of configuration at silicon thus implies that approach of the hydride donor on the chiral silyl cation should occur with inversion of configuration, as shown in $\mathbf{7}$ and $\mathbf{8 b}$ (X-ray) (Figure 5a), the presence of bulky $t$-Bu and Me substituents respectively in $\mathbf{7}$ and $\mathbf{8 b}$ (?]- to nitrogen) preventing any attack syn to the heterocycle nitrogen. An alternative pathway invoking the formation of a transitory pentacoordinated silicon intermediate appears unlikely, DFT calculations showing that such an intermediate is not an energy minimum (SI). It may thus be concluded that the overall retention of configuration observed for silane 2 results from a double inversion during abstraction then silyl-cation hydride trapping. A possible scenario summarizing the $\mathbf{2} \rightarrow \mathbf{7} \rightarrow \mathbf{2}$ and $\mathbf{3} \rightarrow \mathbf{8 a}-\mathbf{b} \rightarrow \mathbf{3}$ sequences is illustrated in Figure $5 \mathrm{~b}$. The retention of configuration observed in silane $\mathbf{2}$ and partially in $\mathbf{3}$ may thus be rationalized invoking a first inversion at silicon 
during $\mathrm{Si}-\mathrm{H}$ abstraction by the trityl cation, followed by a second inversion upon hydride addition. ${ }^{10}$ Within this picture, pyridine and quinoline nitrogen atoms both assist the cleavage of the $\mathrm{Si}-\mathrm{H}$ bond in a $\mathrm{S}_{\mathrm{N}}$ 2-like fashion and act as leaving groups during reduction, again through a $\mathrm{S}_{\mathrm{N}} 2$-type process. ${ }^{35}$ Analogy should be made here with the well-known "neighboring group participation" in the related carbenium chemistry which ensures, through a double $\mathrm{S}_{\mathrm{N}} 2$ reaction at a saturated carbon, an overall retention of configuration, with the help of an heteroatom lone pair. ${ }^{36}$

The rationalization of the difference of reactivity between silanes $\mathbf{2}$ and $\mathbf{3}$ is less straightforward. As discussed above, silane 2, which silicon substituent is bonded to a $\mathrm{C}_{\mathrm{sp} 3}$ center, leads upon $\mathrm{Si}-\mathrm{H}$ abstraction to a more flexible silyl cation, allowing a facile stabilization of the latter through nitrogen interaction and formation of a less strained four-membered ring nitrogenstabilized-silylium ion in salt $\mathbf{7}$. The stronger Si-N interaction is therefore more likely to maintain the configuration of the silicon center during the (-)-2 $\rightarrow \mathbf{7} \rightarrow(-)-\mathbf{2}$ sequence. In contrast, in silane $\mathbf{3}$, the silicon substituent on a $\mathrm{C}_{\mathrm{sp} 2}$ center offers less flexibility, leading to strained nitrogen-stabilized silyliums in salts $\mathbf{8 a - b}$, to which any Lewis base (LB, Figure $5 \mathrm{~b}$ ) present in the medium (solvent, $\mathrm{Ph}_{3} \mathrm{CH}, \ldots$ ) may eventually add and invert the silicon center even at low temperature (vide infra). This hypothesis is further substantiated looking at the X-ray diffraction studies of $\mathbf{8 b}$ (Figures 3 and 5(a), Table 1), the structure of which exhibits a trigonal pyramidal geometry where the aryl, methyl and $t$-butyl substituents forms a nearly planar arrangement $\left(\Sigma \alpha(\mathrm{Si})=352.76^{\circ}\right)$, leaving much room to Lewis bases present in the medium to approach the silicon center. In comparison, the more pronounced pyramidalization in $7\left(\Sigma \alpha(\mathrm{Si})=345.02^{\circ}\right)$ along with the presence of the $\mathrm{CH}_{2}$ at $\mathrm{C}_{1}$ likely hinders such an approach, and thus protect the silicon center from weak nucleophiles, at low temperature.
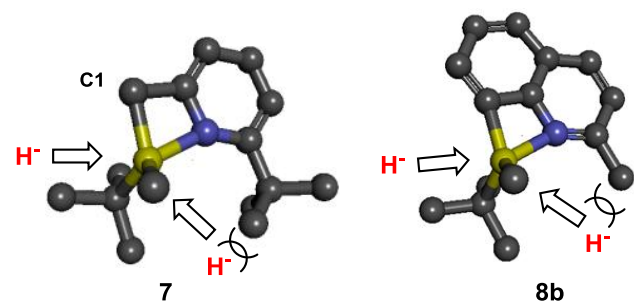

(a)

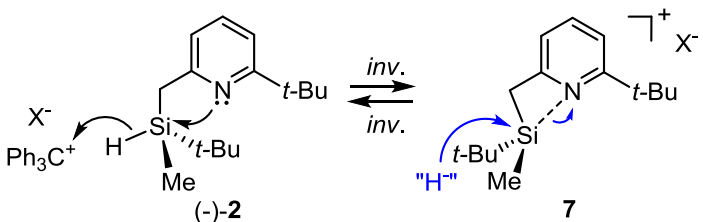

(b)

$(-)-2$

7

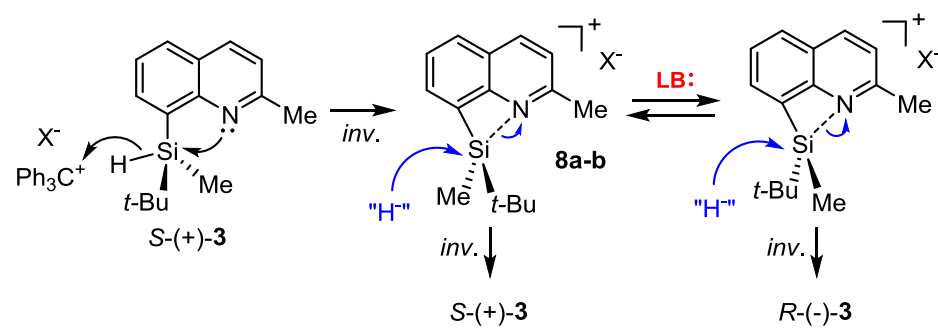

Figure 5. Rationalization of chiral memory in silanes $\mathbf{2}$ and $\mathbf{3}$ (LB: Lewis base)

\section{CONCLUSION}

In summary, we described here the preparation and full characterization of silyl cations stabilized through an intramolecular interaction with pyridine and quinoline nitrogen centers. The Si-N interaction is sufficiently strong to bring the silicon and the nitrogen center close enough to generate stable four-membered ring systems, which structures could be determined through X-ray diffraction studies. The relative strength of the Si-N bond in these cations also allowed the first generation of an enantiopure Si-centered chiral silyl cation (e.g. 7). Angle distortions of more than $30^{\circ}$ were observed for the $\mathrm{C}-\mathrm{Si}$ bond due to the interaction between the silyl cation and the nitrogen. The angle strain, along with the variable pyramidalization of the silicon center allow rationalizing the different levels of chiral memory observed in these silanes, depending on the nature of the heterocycle. The strength of the Si-N interaction thus depends on the hybridization of the carbon center to which the silicon atom is bonded $\left(\mathrm{C}_{\mathrm{sp} 3} v s \mathrm{C}_{\mathrm{sp} 2}\right)$, which modulates the flexibility of the system and consequently the ability of nitrogen to stabilize the positive charge at silicon. Structures available through XRDS provide an understanding of the silyl cation formation/hydride addition sequence, allowing the drawing of a complete picture of the stereochemical events during the process. The anchimeric assistance of the pyridine or quinoline ring is thus shown, for 
which it is useful to highlight the analogy with neighboring group participation observed in related carbenium chemistry. ${ }^{36}$ The complete retention of the chirality in silyl cations such as $\mathbf{7}$, associated to the labile nature of the $\mathrm{N}$-Si interaction (in the presence of an external nucleophile) might allow further use of these silyl cations with Si-centered chirality in enantioselective asymmetric catalysis.

\section{REFERENCES}

(1) For reviews on silylium ions chemistry, see: (a) Corriu, R. J. P.; Henner, M. The Siliconium lon Question. J. Organomet. Chem. 1974, 74, 1-28. (b) Müller, T. Silylium ions and stabilized silylium ions in Science of Synthesis, Knowledge updates 2013/3, Vol. Ed.: M. Oestreich, G. Thieme Verlag KG, Stuttgart, 2013, pp. 1-42. (c) Klare, H. F. T.; Oestreich, M. New Horizon of Organosilicon Chemistry. Dalton Trans 2010, 39, 9176-9184. (d) Sekiguchi, A.; Lee, V. Y. Organometallic compounds of low-coordinate Si, Ge, Sn and Pb, 2010, Wiley, Chichester. For recent isolation and characterization of silylium ions, see: (e) Wu, Q.; Irran, E.; Müller, R.; Kaupp, M.; Klare, H. F. T.; Oestreich, M. Characterization of hydrogensubstituted silylium ions in the condensed phase. Science, 2019, 365, 168-172. (f) Walker, J. C. L.; Klare, H. F. T.; Oestreich, M. Cationic silicon Lewis acids in catalysis. Nat. Rev. Chem., 2019, doi.org/10.1038/s41570-019-0146-7. (g) Siegel, J. S. Silylium ions: from controversial beginnings to useful catalysts. Nat. Rev. Chem., 2019, DOI: 10.1038/s41570-019-0151-x.

(2) (a) Duttwyler, S.; Do, Q.-Q.; Linden, A.; Baldridge, K. K.; Siegel, J. S. Synthesis of 2,6-Diarylphenyldimethylsilyl Cations: Polar- $\pi$-Distribution of Cation Character. Angew. Chem. 2008, 120, 1743-1746; Angew. Chem. Int. Ed., 2008, 47, 1719-1722. (b) Romanato, P.; Duttwyler, S.; Linden, A.; Baldridge K. K.; Siegel, J. S. Intramolecular Halogen Stabilization of Silylium Ions Directs Gearing Dynamics. J. Am. Chem. Soc. 2010, 132, 78287829. (c) Romanato, P.; Duttwyler, S.; Linden, A.; Baldridge K. K.; Siegel, J. S. Competition between $\pi$-Arene and Lone-Pair Halogen Coordination of Silylium lons ? J. Am. Chem. Soc. 2011, 133, 11844-11846. (d) Chauhan, M.; Chuit, C.; Corriu, R. J. P.; Mehdi, A.; Reyé, C. Study of Silyl Cations Bearing an Aryldiamine Pincer Ligand Organometallics, 1996, 15, 4326-4333. (e) Müller, T. A Silyl Cation with a Three-Center Si-H-Si Bond. Angew. Chem. 2001, 113, 3123-3126; Angew. Chem. Int. Ed. 2001, 40, 3033-3036. (f) Khalimon, A. Y.; Lin, Z. H.; Simionescu, R.; Vyboishchikov, S. F.; Nikonov, G. I. Persistent Silylium Ions Stabilized by Polyagostic Si-H ‥Si Interactions. Angew. Chem. 2007, 119, 4614-4617; Angew. Chem. Int. Ed. 2007, 46, 4530-4533. (g) Lehmann, M.; Schulz, A.; Villinger, A. Bissilylated Halonium lons: $\left[\mathrm{Me}_{3} \mathrm{Si}-\mathrm{X}-\mathrm{SiMe} \mathrm{S}_{3}\right]\left[\mathrm{B}\left(\mathrm{C}_{6} \mathrm{~F}_{5}\right)_{4}\right](\mathrm{X}=\mathrm{F}, \mathrm{Cl}, \mathrm{Br}, \mathrm{I})$. Angew. Chem. 2009, 121, 7580-7583; Angew. Chem. Int. Ed. 2009, 48, 7444-7447. (h) Müther, K.; Fröhlich, R.; Mück-Lichtenfeld, C.; Grimme, S.; Oestreich, M. A Unique Transition Metal-Stabilized Silicon Cation. J. Am. Chem. Soc. 2011, 133, 12442-12444. (i) Ibad, M. F.; Langer, P.; Schulz, A.; Villinger, A. Silylium-Arene Adducts: An Experimental and Theoretical Study. J. Am. Chem. Soc. 2011, 133, 21016-21027. (j) Müther, K.; Hrobarik, P.; Hrobarikova, V.; Kaupp, M.; Oestreich, M. The Family of Ferrocene-Stabilized Silylium lons: Synthesis, ${ }^{29}$ Si NMR Characterization, Lewis Acidity, Substituent Scrambling, and Quantum-Chemical Analyses. Chem. Eur. J. 2013, 19, 16579-16594. (k) Reißmann, M.; Schäfer, A.; Panisch, R.; Schmidtmann, M.; Bolte, M.; Müller, T. Cyclic Silylated Onium lons of Group 15 Elements. Inorg. Chem. 2015, 54, 2393-2402. (I) Rohde, V. H. G.; Pommerening, P.; Klare, H. F. T.; Oestreich, M. Intramolecularly Sulfur-Stabilized Silicon Cations as Lewis Acid Catalysts. Organometallics 2014, 33, 3618-3628. (m) Albers, L.; Aghazadeh Meshgi, M.; Baumgartner, J.; Marschner, C.; Müller, T. Wagner-Meerwein-Type Rearrangements of Germa-polysilanes - A Stable Ion Study. Organometallics 2015, 34, 3756-3763. (n) Chen, Q.-A.; Klare, H. F. T.; Oestreich, M. Brønsted AcidPromoted Formation of Stabilized Silylium Ions for Catalytic Friedel-Crafts C-H Silylation. J. Am. Chem. Soc. 2016, 138, 7868-7871. (o) Arii, H.; Yano, Y.; Nakabayashi, K.; Yamaguchi, S.; Yamamura, M.; Mochida, K.; Kawashima, T. Regioselective and Stereospecific Dehydrogenative Annulation Utilizing Silylium Ion-Activated Alkenes. J. Org. Chem. 2016, 81, 6314-6319.

(3) (a) Olah, G. A. Stable carbocations. CXVIII. General concept and structure of carbocations based on differentiation of trivalent (classical) carbenium ions from three-center bound penta- of tetracoordinated (nonclassical) carbonium ions. Role of carbocations in electrophilic reactions. J. Am. Chem. Soc. 1972, 94, 808-820. (b) Olah, G. A. 100 Years of Carbocations and Their Significance in Chemistry. J. Org. Chem. 2001, 66, 5943-5957.

(4) Kim, K.-C.; Reed, C. A.; Elliott, D. W.; Mueller, L. J.; Tham, F.; Lin, L.; Lambert, J. B. Crystallographic Evidence for a Free Silylium lon. Science 2002, 297, 825-827.

(5) (a) Hara, K.; Akiyama, R.; Sawamura, M. Strong Counteranion Effects on the Catalytic Activity of Cationic Silicon Lewis Acids in Mukaiyama Aldol and Diels-Alder Reactions. Org. Lett. 2005, 7, 5621-5623. (b) Schmidt, R. K.; Müther, K.; Mück-Lichtenfeld, C.; Grimme, S.; Oestreich, M. Silylium Ion-Catalyzed Challenging Diels-Alder Reactions: The Danger of Hidden Proton Catalysis with Strong Lewis Acids. J. Am. Chem. Soc. 2012, 134, 4421-4428. (c) Klare, H. F. T.; Bergander, K.; Oestreich, M. Taming the Silylium lon for Low-Temperature Diels-Alder Reactions. Angew. Chem. 2009, 121, 9241-9243; Angew. Chem. Int. Ed. 2009, 48, 9077-9079. (d) Nödling, A. R.; Müther, K.; Rohde, V. H. G.; Hilt, G.; Oestreich, M. Ferrocene-Stabilized Silicon Cations as Catalysts for Diels-Alder Reactions: Attempted Experimental Quantification of Lewis Acidity and ReactlR Kinetic Analysis. Organometallics 2014, 33, 302-308.

(6) (a) Scott, V. J.; Remle, Ç.-Ç.; Ozerov, O. V. Room-Temperature Catalytic Hydrodefluorination of C(sp ${ }^{3}$ )-F Bonds. J. Am. Chem. Soc. 2005, 127, 2852-2853. (b) Douvris, C.; Ozerov, O. V. Hydrodefluorination of Perfluoroalkyl Groups Using Silylium-Carborane Catalysts. Science, 2008, 321, 1188-1190. (c) Douvris, C.; Nagaraja, C. M.; Chen, C.-H.; Foxman, B. M.; Ozerov, O. V. Hydrodefluorination and Other Hydrodehalogenation of Aliphatic Carbon-Halogen Bonds Using Silylium Catalysis. J. Am. Chem. Soc. 2010, 132, 4946-4953. (d) Panisch, R.; Bolte, M.; Müller, T. Hydrogenand Fluorine-Bridged Disilyl Cations and Their Use in Catalytic C-F Activation. J. Am. Chem. Soc. 2006, 128, 9676-9682. (e) Lühmann, N.; Hirao, H.; Shaik, S.; Müller, T. Disilylfluoronium lons-Synthesis, Structure, and Bonding. Organometallics 2011, 30, 4087-4096. (f) Lühmann, N.; Panisch, R.; Müller, T. A catalytic C-C bond-forming reaction between aliphatic fluorohydrocarbons and arylsilanes. Appl. Organomet. Chem. 2010, 24, 533537. (g) Allemann, O.; Duttwyler, S.; Baldridge, K. K.; Siegel, J. S. Proton-Catalyzed, Silane-Fueled Friedel-Crafts Coupling of Fluoroarenes. Science 2011, 332, 574-577. (h) Stahl, T.; Klare, H. F. T.; Oestreich, M. Main-Group Lewis Acids for C-F Bond Activation. ACS Catal. 2013, 3, 1578-1587. (i) Kordts, N.; Künzler, S.; Rathjen, S.; Sieling, T.; Großekappenberg, H.; Schmidtmann, M.; Müller, T. Silyl Chalconium lons: Synthesis, Structure and Application in Hydrodefluorination Reactions. Chem. Eur. J. 2017, 23, 10068-10079. (j) Mallov, I.; Ruddy, A. J.; Zhu, H.; Grimme, S.; Stephan, D. W. 
C-F Bond Activation by Silylium Cation/Phosphine Frustrated Lewis Pairs: Mono-Hydrodefluorination of $\mathrm{PhCF}_{3}, \mathrm{PhCF}_{2} \mathrm{H}_{\text {and }} \mathrm{Ph}_{2} \mathrm{CF}_{2}$. Chem. Eur. J. 2017, 23, 17692-17696.

(7) (a) Schäfer, A.; Reißmann, M.; Schäfer, A.; Saak, W.; Haase, D.; Müller T. A New Synthesis of Triarylsilylium lons and Their Application in Dihydrogen Activation. Angew. Chem. 2011, 123, 12845-12848; Angew. Chem. Int. Ed. Engl., 2011, 50, 12636-12638. (b) Reißmann, M.; Schäfer, A.; Jung, S.; Müller, T. Silylium Ion/Phosphane Lewis Pairs. Organometallics 2013, 32, 6736-6744.

(8) (a) Omann, L.; Qu, Z.-W.; Irran, E.; Klare, H. F. T.; Grimme, S.; Oestreich, M. Electrophilic Formylation of Arenes by Silylium lon Mediated Activation of Carbon Monoxide. Angew. Chem. Int. Ed. 2018, 57, 8301-8305. (b) Devillard, M.; de Bruin, B.; Siegler, M. A.; van der Vlugt, J. I. Transition-Metal-Free Cleavage of CO. Chem. Eur. J. 2017, 23, 13628-13632.

(9) (a) Schmidt, R. K.; Klare, H. F. T.; Fröhlich, R.; Oestreich, M. Planar Chiral, Ferrocene-Stabilized Silicon Cations. Chem. Eur. J. 2016, 22, 53765383. (b) Rohde, V. H. G.; Müller, M. F.; Oestreich, M. Intramolecularly Sulfur-Stabilized Silicon Cations with Chiral Binaphthyl Backbones: Synthesis of Three Different Motifs and their Application in Enantioselective Diels-Alder Reactions. Organometallics 2015, 34, 3358-3373. (c) Shaykhutdinova, P.; Kemper, S.; Oestreich, M. Refinement of the Catalyst Backbone of Chiral Intramolecular Silicon-Sulfur Lewis Pairs: Improved Enantioselectivity in the Diels-Alder Reaction of Cyclohexa-1,3-diene and Chalcone Derivatives. Eur. J. Org. Chem. 2018, 2896-2901. (d) Pommerening, P.; Mohr, J.; Friebel, J.; Oestreich, M. Synthesis of a Chiral Borate Counteranion, Its Trityl Salt, and Application Thereof in LewisAcid Catalysis. Eur. J. Org. Chem. 2017, 2312-2316. (e) Shaykhutdinova, P.; Oestreich, M. Further Structural Modification of Sulfur-Stabilized Silicon Cations with Binaphthyl Backbones. Synthesis 2019, 51, 2221-2229.

(10) Ducos, P.; Liautard, V.; Robert, F.; Landais, Y. Chiral Memory in Silylium Ions. Chem. Eur. J. 2015, 21, 11573-11578.

(11) For an example of 5-membered ring stabilized silyl-pyridinium, see: (a) Nokami, T.; Soma, R.; Yamamoto, Y.; Kamei, T.; Itami, K.; Yoshida, J. Generation of pyridyl coordinated organosilicon cation pool by oxidative Si-Si bond dissociation. Beilstein J. Org. Chem. 2007, 3, No. 7. (b) Chauban, M.; Chuit, C.; Corriu, R. J. P.; Mehdi, A.; Reyé, C. Study of silyl cations bearing an aryldiamine pincer ligand. Organometallics 1996, 15, 4326-4333.

(12) (a) Zheng, Z.; Elmkaddem, M. K.; Fischmeister, C.; Roisnel, T.; Thomas, C. M.; Carpentier, J.-F.; Renaud, J.-L. Synthesis of new dipyridinylamine and dipyridinylmethane ligands and their coordination chemistry with $\mathrm{Mg}$ (II) and $\mathrm{Zn}$ (II). New J. Chem. 2008, 32, 2150-2158. (b) Körte, L. A.; Warner, R.; Vishnevskiy, Y. V.; Neumann, B.; Stammler, H.-G.; Mitzel, N. W. Intramolecular pyridine-based frustrated Lewis-pairs. Dalton Trans. 2015, 44, 9992-10002. (c) Lord, A.-M.; Mahon, M. F.; Lloyd, M. D.; Threadgill, M. D. Design, Synthesis, and Evaluation in Vitro of Quinoline-8-carboxamides, a New Class of Poly(adenosine-diphosphate-ribose)polymerase-1 (PARP-1) Inhibitor. J. Med. Chem. 2009, 52, 868-877.

(13) Pramanik, S.; Fernandes, A.; Liautard, V.; Pucheault, M.; Robert, F.; Landais, Y. Dehydrogenative Silylation of Alcohols Under PdNanoparticle Catalysis. Chem. Eur. J. 2019, 25, 728-732.

(14) Trepohl, V. T.; Fröhlich, R.; Oestreich, M. Conjugate phosphination of cyclic and acyclic acceptors using Rh(I)-phosphine or Rh(I)-carbene complexes. Probing the mechanism with chirality at the silicon atom or the phosphorus atom of the Si-P reagent. Tetrahedron 2009, 65, 65106518.

(15) (a) Oestreich, M.; Auer, G.; Keller, M. On the Mechanism of the Reductive Metallation of Asymmetrically Substituted Silyl Chlorides. Eur. J. Org. Chem. 2005, 184-195. (b) Rendler, S.; Auer, G.; Keller, M.; Oestreich, M. Preparation of a Privileged Silicon-Stereogenic Silane: Classical versus Kinetic Resolution. Adv. Synth. Catal. 2006, 348, 1171-1182.

(16) Karnezis, A.; O'Hair, R. A. J.; White, J. M. Desilylation of $\beta$-Silyl Pyridinium Ions: Gas-Phase and Solution-Phase Studies in Conjunction with DFT Calculations. Organometallics 2009, 28, 4276-4282.

(17) Gong, B.-Q.; Chen, W.-Y.; Hu, B.-F. The X-Ray Crystal Structure and Packing Mode of ( \pm )-2-Thiono-2-Mercapto-A,A'-Dinaphtho-(d,f)(1,3,2)Dioxophosphepin - A Clathrate Structure. Phosphorus Sulfur Silicon Relat. Elem. 1991, 57, 87-94.

(18) As the determination of the absolute configuration of enantiomers of $\mathbf{2}$ could not be obtained through X-ray diffraction studies of the oily silyl ethers $\mathbf{4} \mathbf{a}-\mathbf{b}$, absolute configuration of both enantiomers of $\mathbf{2}$ have been attributed arbitrarily and will simply be noted (-)-2 and (+)-2 in the rest of the article.

(19) (a) Bartlett, P. D.; Condon, F. E.; Schneider, A. Exchanges of Halogen and Hydrogen between Organic Halides and Isoparaffins in the Presence of Aluminum Halides. J. Am. Chem. Soc. 1944, 66, 1531-1539. (b) Corey, J. Y. Generation of a Silicenium Ion in Solution. J. Am. Chem. Soc. 1975, 97, 3237-3238.

(20) No competitive $\mathrm{N}$-alkylation of pyridine $\mathbf{2}$ or $\mathbf{3}$ with the trityl cation was observed. However, careful examination through ${ }^{1} \mathrm{H}$ NMR (1D and 2D) of model reactions between pyridine and 2,6-dimethylpyridine with $\left[\mathrm{Ph}_{3} \mathrm{C}\right]\left[\mathrm{B}\left(\mathrm{C}_{6} \mathrm{~F}_{5}\right)_{4}\right]$, revealed that a weak Lewis adduct is likely formed, which then disappears upon addition of the silane (see SI for a discussion).

(21) (a) Lambert, J. B.; Zhang, S.; Ciro, S. M. Silyl Cations in the Solid and in Solution. Organometallics 1994, 13, 2430-2443. (b) See also: Bähr, S.; Oestreich, M. A neutral Ru" hydride complex for the regio- and chemoselective reduction of N-silylpyridinium ions. Chem. Eur. J. 2018, 24, 5613-5622.

(22) Chénard, E.; Sutrisno, A.; Zhu, L.; Assary, R. S.; Kowalski, J. A.; Barton, J. L.; Bertke, J. A.; Gray, D. L.; Brushett, F. R.; Curtiss, L. A.; Moore, J. S. Synthesis of Pyridine- and Pyrazine-BF 3 Complexes and Their Characterization in Solution and Solid State. J. Phys. Chem. C 2016, 120, 84618471.

(23) Morris, K. F.; Johnson, C. S. Jr. Diffusion-ordered two-dimensional nuclear magnetic resonance spectroscopy. J. Am. Chem. Soc., 1992, 114, 3139-3141.

(24) Pregosin, P. S. Ion pairing using PGSE diffusion methods. Nucl. Magn. Reson. Spect. 2006, 49, 261-288.

(25) Hensen, K.; Zengerly, T.; Pickel, P.; Klebe, G. [Me ${ }_{3} \mathrm{Si}(\mathrm{py}]^{+} \mathrm{X}(\mathrm{X}=\mathrm{Br}, \mathrm{I})$ : X-Ray Structural Analysis of the 1 : 1-Adducts of Bromo- or lodotrimethylsilane and Pyridine. Angew. Chem. Int. Ed. 1983, 22, 725-726.

(26) The N-Si bond length in 7 was compared with that of a structurally related iminosilane $\mathrm{R}_{2} \mathrm{C}=\mathrm{N}-\mathrm{SiMe}_{3}$ : (a) Bowen, R. J.; Fernandes, M. A.; Gitari, P. W.; Layh, M.; Moutloali, R. M. Synthesis and Reactions of Mixed N,P Ligands. Eur. J. Inorg. Chem. 2005, 31955-1963.

(27) Waked, A. E.; Chitnis, S. S.; Stephan, D. W. P(V) dications: carbon-based Lewis acid initiators for hydrodefluorination. Chem. Commun. 2019, 55, 8971-8974. 
(28) (a) Reed, C. A. Carboranes: A New Class of Weakly Coordinating Anions for Strong Electrophiles, Oxidants, and Superacids. Acc. Chem. Res. 1998, 31, 133-139. (b) Riddlestone, I. M.; Kraft, A.; Schaefer, J.; Krossing. I. Taming the Cationic Beast: Novel Developments in the Synthesis and Application of Weakly Coordinating Anions. Angew. Chem. Int. Ed. 2018, 57, 13982-14024. (c) Fisher, S. P.; Tomich, A. W.; Lovera, S. O.; Kleinsasser, J. F.; Guo, J.; Asay, M. J.; Nelson, H. M.; Lavallo, V. Non classical Applications of closo-Carborane Anions: From Main Group Chemistry and Catalysis to Energy Storage. Chem. Rev. 2019, 119, 8262-8290.

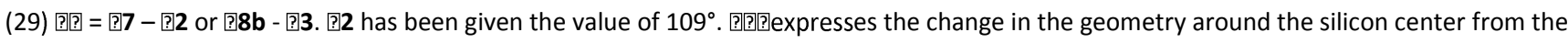
parent silane to the silyl cation due to the $\mathrm{N}-\mathrm{Si}$ interaction and should be indicative of the strain in the cation.

(30) Similar experiments carried out on an analogue of $\mathbf{2}$ bearing a $\mathrm{Si}(t-\mathrm{Bu})_{2}$ substituent led to the recovery of the silane with a protonated pyridine nucleus, suggesting that a $\left(n-\mathrm{Bu}_{3} \mathrm{Sn}\right)$ cation (stabilized through a Wheland type complex with $\mathrm{Ph}_{3} \mathrm{CH}$ or the solvent) was formed during the process, acting as a source of proton.

(31) 1,2- or 1,4-Addition of these hydrides onto the pyridine ring to provide the corresponding cyclohexadienylsilanes were not observed. ${ }^{21 b}$ Gutsulyak, D. V.; van der Est, A.; Nikonov, G. I. Facile catalytic hydrosilylation of pyridines. Angew. Chem. Int. Ed. 2011, 50, 1384-1387. In contrast, addition of Grignard and organo-lithium reagents led to complex mixtures.

(32) Durka, K.; Urban, M.; Czub, M.; Dabrowski, M.; Tomasewski, P.; Lulinski, S. An intramolecular ortho-assisted activation of the siliconhydrogen bond in arylsilanes: an experimental and theoretical study. Dalton Trans. 2018, 47, 3705-3716.

(33) (a) Chuit, C.; Corriu, R. J. P.; Reye, C.; Young, J. C. Reactivity of Penta- and Hexacoordinate Silicon Compounds and Their Role as Reaction Intermediates. Chem. Rev. 1993, 93, 1371-1448. (b) Corriu, R. J. P.; Royo, G.; De Saxcè, A. Pentaco-ordinate Silicon Derivatives : ${ }^{1} \mathrm{H}$ NMR Evidence. J. Chem. Soc., Chem. Commun. 1980, 892-894.

(34) Boyer, J.; Brelière, C.; Carré, F.; Corriu, R. J. P.; Kpoton, A.; Poirier, M.; Royo, G.; Young, J. C. Five co-ordinated Silicon Compounds: Geometry of Formation of Intramolecular Co-ordination. Crystal Structure of 2-(Dimethylaminomethyl)phenyl-1-naphthylsilane. J. Chem. Soc., Dalton Trans 1989, 43-51.

(35) Corriu, R. J. P.; Guérin, C.; Moreau, J. J. E. in Topics in Stereochemistry; Ed.: E. L. Eliel, Wiley: New York, 1984; Vol. 15, pp. 43-198.

(36) For a review, see: Capon, B. Neighbouring Group Participation. Quat. Rev. Chem. Soc. 1964, 18, 45-111. For specific examples including the participation of a pyridine ring in anchimeric assistance, see: Capon, B.; McManus, S. P., Neighboring Group Participation, Plenum Press, New-Yor, 1976, Vol. 1, pages 128 and 253. 